\title{
MAGNITUDE DO DISTRITO E FRAGMENTAÇÃO PARTIDÁRIA NO SISTEMA DE REPRESENTAÇÃO PROPORCIONAL DE LISTA ABERTA
}

Yuri Lucatelli Taba ${ }^{1}$

\begin{abstract}
Resumo
Em sistemas de representação proporcional com distritos de magnitude alta, mudanças no número de cadeiras em disputa afetam o número de partidos? Estudos sobre os efeitos políticos da magnitude do distrito constituem um dos pilares da disciplina e, portanto, não são novidade. Parte deste debate tem como pano de fundo a dificuldade de identificar o efeito causal de instituições eleitorais, sobretudo com a discussão sobre a endogeneidade dos efeitos das regras sobre o número de partidos. Contribuições recentes na literatura objetivam superar estes obstáculos ao adotar desenhos de pesquisa focados na explicação causal dos efeitos destas instituições separadamente. No caso brasileiro há ainda mais incerteza. A literatura indica maior dificuldade em verificar os efeitos da magnitude sobre o número de partidos em distritos com mais de cinco cadeiras em disputa. Utilizando mudanças de magnitude desencadeadas pela Justiça Eleitoral e pelo Congresso Nacional e partindo com uma abordagem por differences-in-differences, este trabalho, ainda em andamento, traz evidências de que o aumento da magnitude em pequenos municípios brasileiros causou aumento no número de partidos no distrito.
\end{abstract}

Palavras-Chave: inferência causal; magnitude do distrito; fragmentação partidária; instituições eleitorais; representação proporcional de lista aberta.

\section{INTRODUÇÃO}

O estudo sobre os efeitos das regras eleitorais é um dos principais objetos de estudo da ciência política e conta com vasta produção teórica e empírica. Neste trabalho, pretende-se destacar os efeitos de uma instituição eleitoral específica, a magnitude do distrito, sobre o sistema partidário. Esta relação é a mais estudada pela literatura, porém não é a única, uma vez que há uma variedade de trabalhos que verificam a relação entre magnitude do distrito e outros resultados políticos, como por exemplo: corrupção (Chang e Golder, 2007), performance econômica (Coppedge, 1997), gastos governamentais (Edwards e Thomes, 2007) entre outros.

\footnotetext{
1. Departamento de Ciência Política da Universidade de São Paulo, ytaba@usp.br.
} 
Como se verá, a relação entre as variáveis estudadas é evidente em grande parte dos sistemas eleitorais chamados majoritários, sobretudo os de plurality, contando com algumas evidências para sistemas de representação proporcional. Entretanto, estas evidências encontram barreiras a partir de um determinado tamanho de magnitude do distrito, a partir do qual os mecanismos teorizados para a explicação do efeito da magnitude sobre o sistema partidário passam a ser menos discerníveis (Cox, 1997). Tendo este obstáculo em vista, este trabalho propõe evidências sobre a relação estudada sob o sistema de representação proporcional de lista aberta vigente no Brasil, que conta com magnitude considerada alta pela literatura.

De início, apresento uma revisão de parte da longa produção sobre o assunto. Esta revisão posiciona a pergunta de pesquisa que direcionará a análise empírica apresentada na seção 3: em sistemas de representação proporcional com distritos de magnitude alta, mudanças no número de cadeiras em disputa afetam o número de partidos?

Para encaminhar uma resposta, mobilizo dados de eleições municipais brasileiras com um desenho de pesquisa que foca nas mudanças de magnitude do distrito realizadas a partir da Justiça Eleitoral e do Congresso Nacional. Este desenho de pesquisa tem como objetivo aproximar este trabalho de parte das produções recentes da literatura ao buscar a identificação causal dos efeitos das regras eleitorais.

Os resultados até agora encontrados seguem, de maneira geral, o apresentado pela teoria: aumento da magnitude do distrito causa maior fragmentação partidária ao nível do distrito.

Por fim, destaca-se que esta é uma pesquisa em andamento. Os resultados aqui apresentados, mesmo que robustos em diversas especificações de variáveis dependente, inclusão de efeitos fixos e testes placebo, serão ainda abordados por outras técnicas e desenhos de pesquisa, conforme exposto ao início da seção 3.

\section{INSTITUIÇÕES ELEITORAIS E O SISTEMA PARTIDÁRIO}

Esta seção conta com uma breve revisão da bibliografia sobre a relação entre leis eleitorais e o número efetivo de partidos.2

\subsection{O INSTITUCIONALISMO "PURO"}

\footnotetext{
2 Ao longo do texto, quando há referência ao número efetivo de partidos, considero o resultado da fórmula desenvolvida por Laakso and Taagepera (1979).
} 
Ainda que se tenha ciência de estudos sobre as consequências das regras eleitorais ao menos desde o século $\mathrm{XIX}_{3}$, esta temática recebeu atenção crescente a partir dos trabalhos de Maurice Duverger (1951) e Douglas Rae (1967). Enquanto a teoria de Duverger mobiliza pesquisas até hoje, talvez o principal ponto de início da literatura empírica foi o livro de Rae "The political consequences of electoral laws".

As proposições de Duverger (1951) se referem, de maneira geral, à questão do número de partidos que compõem um sistema partidário sob determinadas regras e estrutura social ao nível do distrito. Riker (1982) as organizou em duas partes: a primeira é a Lei de Duverger, a qual propõe que leis eleitorais de maioria simples (plurality) e de cédula única com um turno favorecem um sistema bipartidário, não importando as clivagens sociais existentes; e a segunda é a Hipótese de Duverger, que constata a tendência de não redução do número de legendas em sistemas eleitorais de representação proporcional ou que possuam segundo turno, caso o número de clivagens sociais incentive a formação de mais partidos. Como será notado adiante, estas ideias fazem parte de um raciocínio mais complexo, mas, a título de clareza e objetividade, as proposições serão assim chamadas a partir de agora.

Nota-se que o número de cadeiras a serem preenchidas pelo processo eleitoral é um componente crucial para a teoria. A magnitude do distrito é considerada a principal variável do sistema eleitoral, sendo, portanto, um importante objeto de interesse para estudos das instituições eleitorais. Por ser facilmente quantificada e comparada, a variável faz parte dos principais textos da literatura.

Com a finalidade de apontar os mecanismos pelos quais as regras eleitorais influem no sistema partidário, Duverger (1951) separou os efeitos mecânicos dos psicológicos. No primeiro caso, trata-se da tradução direta de votos em assentos e a desproporcionalidade que os sistemas eleitorais tendem a trazer, por exemplo, sub-representando partidos menores. Desta maneira, ao passar para os efeitos psicológicos, tal sub-representação dos pequenos partidos pode servir de incentivo para a deserção de eleitores destas agremiações, fenômeno chamado posteriormente de "voto estratégico". Outro fator psicológico seria a antecipação do efeito mecânico por parte das elites partidárias, que poderiam repensar a entrada nas eleições - fenômeno estudado pela literatura sob o termo "entrada estratégica" (Cox, 1997).

Se por um lado a identificação dos efeitos mecânicos é simples, já que se pode comparar a proporção de votos de um partido com a proporção de assentos por ele conquistados, o efeito

\footnotetext{
${ }_{3}$ Referência ao livro de John Stuart Mill (1861) “Considerations on representative government”, conforme exposto em Riker (1986).
} 
psicológico é um pouco mais difícil de ser computado devido a seu caráter estratégico que pode não trazer resultados imediatos por depender da coordenação dos atores.

Embora muitos trabalhos relevantes tenham sido escritos sobre os efeitos mecânicos das regras eleitorais em si (sobretudo Taagepera and Shugart, 1989), este trabalho direciona sua atenção para os efeitos psicológicos, o que não limita a abrangência de estudo das consequências das instituições eleitorais, já que, como visto, os efeitos psicológicos são resultados das expectativas dos atores criadas a partir de leituras sobre os efeitos mecânicos.

Esta conjunção dos efeitos é observada no trabalho de Rae (1967) ao estabelecer como variáveis dependentes a proporcionalidade do resultado eleitoral (resultado do efeito mecânico) e o grau de multipartidarismo (resultado do efeito psicológico). $\mathrm{O}$ autor analisa eleições separadamente, mobilizando dados de 20 democracias com eleições entre 1945 e 1965. Como variáveis independentes, utiliza a fórmula eleitoral, média da magnitude do distrito e a estrutura da cédula (que verifica se o eleitor pode dividir seu voto em dois partidos ou mais). Ele encontra uma relação forte entre as variáveis, sugerindo, sobretudo, que na medida em que a magnitude do distrito aumenta, a desproporcionalidade diminui e a tendência ao multipartidarismo aumenta, fornecendo evidências favoráveis às proposições de Duverger.

Uma importante contribuição teórica de Rae para os estudos sobre as consequências das instituições eleitorais na política é a caracterização dos proximal e distal effects, que se referem a "distância" entre a causa e o efeito esperados. Os distal effects são aqueles em que fatores intervenientes devem operar para que a cadeia causal seja concretizada, portanto, são comparáveis aos efeitos psicológicos apontados por Duverger, para os quais é preciso passar pelo comportamento estratégico dos atores e por outras variáveis para que o efeito esperado seja encontrado.

A partir dos testes de Rae, o número de estudos empíricos sobre a relação entre sistema eleitoral e sistema partidário cresceu vertiginosamente. Muitas das produções tentaram replicar seus achados mobilizando novas bases de dados e debatendo sobre qual seria a melhor forma de mensuração das variáveis. Para Shugart (2005), estes estudos tinham dimensão macro e buscavam generalizações sobre estas relações. Um exemplo importante é Lijphart (1990), que muda a abordagem de Rae de análise separada de eleições, considerando que "eleições sob as mesmas regras não são realmente casos independentes, mas meramente operações repetidas do mesmo sistema eleitoral” (p.3). Dessa forma, a unidade de análise passa a ser o sistema eleitoral. 
Os resultados encontrados por Lijphart apresentam algumas diferenças relevantes. Embora o efeito das variáveis do sistema eleitoral (fórmula e magnitude do distrito) permaneçam sobre a desproporcionalidade, o mesmo não ocorre quando se olha para o multipartidarismo. Ao controlar pela magnitude do distrito, Lijphart verifica que o efeito dela sobre o número de partidos é consideravelmente menor que o verificado anteriormente por Rae.

Ao demonstrarem a importância das instituições e suas consequências para o sistema partidário, os autores acima citados, entre diversos outros, estabeleceram uma das principais bases da literatura institucionalista no campo da ciência política. Muitas críticas foram direcionadas à esta concepção, sobretudo às proposições de Duverger. Conforme exposto por Cox (1997), por um lado, críticos apontam um erro na direção de causalidade da teoria: para eles são os sistemas partidários que determinam os sistemas eleitorais, e não o contrário (Grumm, 1958). Por outro, alegam que a literatura focou numa variável pouco importante, visto que o sistema eleitoral seria muito menos relevante para a quantidade de partidos do que o número e tipo de clivagens sociais (Campbell, 1958).

As críticas apontavam muitas vezes para um "determinismo institucionalista" que pretenderia explicar o número de partidos em determinada polity somente com variáveis institucionais. Porém, ainda com base em Cox (1997), muitas das queixas partiram de versões que podem ser chamadas de "social deterministas" por julgarem a estrutura eleitoral como variável endógena e marginalmente determinante, e as clivagens sociais como exógenas e determinantes do sistema partidário, ignorando o problema de ação coletiva ao pressupor que grupos socialmente definidos sempre se organizarão em partidos.

Com a finalidade de verificar a importância das instituições eleitorais e responder às críticas apresentadas, Cox (1997) testa a hipótese de que se caso elas não importassem, o número efetivo de partidos concorrendo às eleições para as câmaras alta e baixa seria o mesmo, a despeito de qualquer mudança no sistema eleitoral entre ambas. Usando "um método natural de controlar pela diversidade social” (p.20, tradução nossa), Cox encontra que, sob a mesma estrutura social, eleições com magnitude maior (em geral para câmaras baixas) apresentam maior número efetivo de partidos.

Embora seja um teste atraente, estudos mais recentes apontam potenciais problemas no estudo de eleições simultâneas para cargos distintos com regras diferentes: para avaliar efeito em determinados resultados políticos provenientes dessa diferença seria necessário assumir que todos os fatores que afetam tal resultado se mantêm constantes, com exceção apenas da regra eleitoral (Fiva e Folke, 2016). Dessa maneira, a existência de partidos organizados somente para disputar (e 
vencer) eleições para a câmara alta, por exemplo, tornaria o resultado do teste enviesado. Obstáculos como este constituem o ponto central deste trabalho e são discutidos adiante.

Seguindo com a breve revisão da literatura, no item seguinte são apresentados estudos que procuram relaxar o determinismo institucional ou social, destacando, sobretudo, o caráter interativo entre regras eleitorais e clivagens sociais presente nas formulações de Duverger.

\subsection{INTERAÇÃO ENTRE INSTITUIÇÕES ELEITORAIS E ESTRUTURA SOCIAL}

Como visto acima, a Hipótese de Duverger traz um componente condicional para que as regras eleitorais ajam como limitadoras do número de partidos. A condição é a de que sendo o sistema eleitoral permissivo - representação proporcional ou eleição com dois turnos - deve haver oferta disponível de grupos que possam ser politicamente ativados na sociedade para que o sistema seja multipartidário.

É com base nesta constatação que trabalhos como Ordershook e Shvetsava (1994) e Amorim Neto e Cox (1997) passaram a abordar a relação entre regras eleitorais e estrutura social como fatores interativos que determinam o número de partidos políticos de uma polity. Estes autores defendem que as explicações institucionalistas e sociológicas para a composição do sistema partidário não são, necessariamente, excludentes. Instituições ou fatores sociais sozinhos não explicam todo o processo, já que nem as regras eleitorais agem sozinhas, nem a heterogeneidade social é inteiramente traduzida no sistema partidário. Com isso, passaram a incluir em seus modelos uma interação entre instituições eleitorais, principalmente a magnitude do distrito, e o número efetivo de grupos étnicos. Nestes dois trabalhos, os autores encontram que o número de partidos depende do produto, ou seja, da interação destas variáveis.

Estes trabalhos, sobretudo Amorim Neto e Cox (1997), consideram que Duverger tomava a estrutura social somente como um erro residual que poderia perturbar o funcionamento correto da instituição eleitoral, permanecendo assim as variáveis institucionais como as cruciais para a explicação do número de partidos. Neste ponto, Clark e Golder (2006) retomam o debate ao expor que a literatura falhava em identificar o processo causal pelo qual a interação entre as variáveis ocorre. Na leitura dos autores, Duverger considera a estrutura social como algo muito maior que apenas um erro residual. Se, por um lado, regras eleitorais representariam a presença ou não de freios para a tendência de multiplicação dos partidos políticos; por outro, forças sociais trariam mais ou menos pressão para esta multiplicação. Dessa forma, as leis eleitorais poderiam liberar a 
concretização de tais pressões para a multiplicação de partidos ou poderiam, ainda, agir como obstáculos a esta multiplicação.

Conforme se pode notar com a diferença das formulações da Lei e Hipótese de Duverger, Riker (1982) considera a desconformidade no grau de determinismo de Duverger com relação a outros sistemas que não os de plurality, mas não chega a perceber que esse menor grau de determinismo se dá justamente pela natureza condicional da teoria. Este seria o ponto em que Clark e Golder (2006) pretendem "reabilitar" a teoria de Duverger, ao afirmar que sua teoria "implica que o número de partidos deveria ser uma função crescente do número de famílias espirituais politicamente salientes numa polity". Sendo assim, "a principal quantia de interesse requerida para avaliar a teoria de Duverger é o efeito marginal de pressões sociais sobre o número de partidos em diferentes níveis de permissividade do sistema eleitoral.” (p.682, tradução nossa).

Se por um lado não se pode abandonar os efeitos da estrutura social, por outro a literatura encontra obstáculos para mensurar esta variável. Conforme visto acima, a teoria fala no número de partidos como uma função do "número de famílias espirituais politicamente ativas" para traduzir a relação entre estrutura social e sistema partidário. Qual seria, então, a medida que deveria ser utilizada para quantificar tais famílias? Até mesmo Clark e Golder (2006) chegam a constatar que a mensuração mobilizada pela literatura (número efetivo de grupos étnicos) representa apenas um elemento da heterogeneidade social e justificam seu uso por esta ser usada em análises anteriores, sendo, portanto, melhor para comparar os resultados. Todavia, deve-se frisar que eventuais problemas de operacionalização do modelo não são corrigidos e o potencial efeito de clivagens sociais sobre o número de partidos permanece incerto.

\subsection{COMPORTAMENTO ESTRATÉGICO DOS ATORES}

Para melhor entendimento dos desdobramentos mais recentes nesta literatura, é necessário voltar para a discussão sobre os mecanismos pelos quais as regras eleitorais afetam a composição e tamanho do sistema partidário, algo feito apenas brevemente nas seções anteriores.

Como vimos, o efeito psicológico apontado por Duverger é um componente crucial por meio do qual sistemas de plurality tendem a gerar bipartidarismo. Este efeito é uma reação que reforça o resultado do efeito mecânico. Ao produzir maior desproporcionalidade, o sistema incentiva a coordenação entre os atores que visam maximizar utilidade. 
Tal coordenação é lida na literatura em duas dimensões distintas: na dos eleitores, sob a alcunha de "voto estratégico", e das elites partidárias, a "entrada estratégica". A generalização e formalização destes conceitos foi desenvolvida por Cox (1997) e ambos contribuem para a regra do " $\mathrm{M}+1$ " formulada pelo autor, que aponta para a tendência de disputa entre $\mathrm{M}+1$ candidatos ou partidos em determinada eleição.

Do lado da demanda, ou seja, dos eleitores, esta regra opera quando o eleitor deixa de votar em seu candidato preferido por este não ser uma das opções viáveis disponíveis. Com isto, o eleitor votaria estrategicamente não em seu candidato preferido entre todos, mas em seu candidato preferido entre os mais bem posicionados na disputa, aqueles com chances concretas de vitória. Evitaria assim que seu voto fosse desperdiçado e aumentaria a chance de se tornar um eleitor crucial (pivotal) neste pleito.

Olhando pelo lado da oferta, as elites partidárias, antecipando a deserção que potencialmente ocorreria por parte de seus eleitores, estrategicamente decidem não entrar na disputa, poupando recursos e abrindo a possibilidade de construção de alguma aliança com outro partido, fator que seria talvez a única maneira do partido influenciar as políticas públicas de alguma maneira.

$\mathrm{Na}$ formulação de Cox, portanto, estes dois fenômenos, embora conceitualmente distintos, direcionam a aplicação da regra do $M+1$, com as elites partidárias fornecendo não mais que $\mathrm{M}+1$ opções para votação ou, caso forneçam, os eleitores não direcionando votos para mais de $\mathrm{M}+1$ candidatos.

Pode-se perceber que há uma série de pressupostos neste raciocínio. Para a noção de voto estratégico, eleitores devem ser instrumentalmente racionais a curto prazo, se importando apenas em influenciar o resultado da eleição (e, logo, devem possuir informação necessária para tanto e capacidade de discerni-las). Com relação à entrada estratégica, o principal pressuposto é o de que o partido deve ter capacidade de identificar muito antes do dia da eleição se será uma alternativa viável para os eleitores, já que esta é a informação que embasaria uma eventual entrada ou retirada do pleito.

Os pressupostos acima destacados dão razão a distinção há muito realizada por Riker (1982) entre Lei e Hipótese de Duverger, visto que a dificuldade de que estes sejam atendidos cresce junto com a magnitude do distrito e, portanto, com a proporcionalidade do sistema eleitoral.

Todavia, Cox (1997) ainda aponta que a regra de $M+1$ pode ser estendida para sistemas de representação proporcional. Os mecanismos pelos quais se chegaria a tal resultado seriam os 
mesmos acima apresentados para o caso de sistemas de plurality e bem funcionariam até que a magnitude do distrito fosse igual a cinco. Ou seja, com M > 5 Cox não identifica o comportamento estratégico necessário para que o sistema eleitoral aja como uma espécie de teto (upper bound) para o número de partidos.

É razoável pensar que conforme a magnitude do distrito aumenta, o nível de informação necessário para o comportamento estratégico dos atores também aumenta. De um lado, partidos enfrentam um obstáculo maior para antecipar seu desempenho eleitoral, visto que agora o cálculo passa a ser de quantos candidatos pode eleger. Do outro lado, eleitores enfrentam maior dificuldade em discernir candidatos viáveis e inviáveis e, assim, podem resistir mais para desertar de seu candidato preferido.

Ainda assim, Abramson et al. (2009) destacam que sistemas multipartidários podem incentivar o voto estratégico na medida em que a escolha do eleitor para votar em um partido ou candidato que não seu preferido pode ser "mais ampla ou menos dramática", sem contar no fator de haver maior probabilidade de que mais de um partido seja uma escolha aceitável para ele (p.83).

Por mais que a complexidade da dinâmica aumente junto com a magnitude do distrito, não se pode inferir não haver comportamento estratégico de atores em contextos com $M>5$, o que se pode tirar disto é que há menor probabilidade de se encontrar voto e entrada estratégicos quando a magnitude é maior e que, portanto, a regra de $M+1$ deve ser repensada nestas situações.

Um sintoma desta discussão é o de que para o caso brasileiro há apenas estudos sobre os fatores aqui estudados em eleições majoritárias, visto que as eleições brasileiras que utilizam o sistema de representação proporcional de lista aberta partem de $\mathrm{M}=8$ para deputados federais, $\mathrm{M}=$ 24 para deputados estaduais e $\mathrm{M}=9$ para vereadores.

Por exemplo, Guarnieri (2015) verifica o voto e entrada estratégicos nas eleições para presidente, governadores e prefeitos. Utiliza um dos indicadores mobilizados por Cox (1997), a "razão SF" na qual se mede a distância entre a votação do primeiro e segundo não eleitos, e encontra evidências favoráveis às formulações de Duverger e Cox: eleições de turno único tendem a ter dois partidos na disputa; eleições com dois turnos e, portanto, análogas a $\mathrm{M}=2$, tendem a apresentar $\mathrm{M}+1$ candidatos (média de número efetivo de candidatos para eleições para governador com dois turnos igual a 2,6). Outros estudos sobre o Brasil serão abordados no item seguinte, devido a particularidades sobre seus desenhos de pesquisa.

Ao longo deste item, tanto o voto estratégico quanto a entrada estratégica foram chamados de mecanismos pelos quais as leis eleitorais afetam o número de partidos ou candidatos. Ainda que 
valiosos para apresentação de um quadro teórico geral, estes não esgotam a explicação de como o processo ocorre, ao dizer pouco, por exemplo, sobre como os eleitores seriam capazes de identificar a força dos partidos ou candidatos (até mesmo o que seria característica de um partido forte) ou, ainda, de como partidos poderiam antecipar seu desempenho eleitoral para decidir sobre a entrada em determinado pleito. Estes pontos são relevantes para melhor entendimento do processo e parecem ser ainda mais valiosos quando o foco do estudo é verificar as propostas de Cox aqui apresentadas para casos em que a magnitude do distrito supera as cinco cadeiras, ponto ainda pouco claro na literatura.

Aparentemente, há aqui um componente de variação contextual relevante, que afeta tanto a aplicação quanto o resultado das regras eleitorais, e que vem sendo objeto de alguma produção na disciplina, como Moser e Scheiner (2012) e Ferree et al. (2014). Talvez esta seja chave crucial para explicação de como regras eleitorais afetam resultados políticos em distritos com $M>5$. Este ponto será discutido com maior atenção em futuras versões deste texto.

\subsection{IDENTIFICAÇÃO CAUSAL DOS EFEITOS DAS REGRAS ELEITORAIS}

Como visto anteriormente, parte da literatura aponta endogeneidade no efeito de regras eleitorais sobre o sistema partidário, alegando que a formação destes sistemas precede a elaboração das leis eleitorais e que, portanto, a relação estaria na direção oposta da estudada por institucionalistas. Com o propósito de superar desconfianças como esta, a produção recente sobre o tema aqui abordado tem se esforçado na busca de oportunidades de desenhos de pesquisa que viabilizam a identificação causal dos efeitos das regras eleitorais de maneira isolada.

O Brasil tem sido um caso muito estudado sob esta perspectiva, por apresentar uma série de intervenções exógenas sobre as regras eleitorais e considerável variação nestas. Fujiwara (2011), por exemplo, verifica o efeito de eleições com um ou dois turnos sobre o voto estratégico e a Lei de Duverger. Para tanto, utiliza uma particularidade das eleições para prefeito no país: turno único em municípios com até 200 mil eleitores; e dois turnos em cidades que ultrapassam este limiar. Com isto, há oportunidade de verificar o efeito causal da mudança das regras em municípios com número de eleitores próximo ao limite, por meio de uma regressão de descontinuidade. Fujiwara encontra que, quando a eleição possui dois turnos, há menor votação para o primeiro e segundo candidatos, evidência que está na linha do teorizado por Duverger e Cox, e dos achados de Guarnieri (2015) para as eleições para Prefeitos e Governadores. 
Outro estudo nesta linha é o de Crisp e Demirkaya (2019) que considera uma particularidade das eleições para o Senado Federal para identificar o efeito causal da mudança de magnitude e da fórmula eleitoral também no voto e entrada estratégicos. Cada estado brasileiro elege três senadores para mandatos de oito anos cada, com eleições ocorrendo a cada quatro anos simultaneamente às eleições gerais para presidente, governadores e deputados. Dessa forma, há variação nas regras eleitorais a cada pleito, já que em uma eleição há apenas uma cadeira em disputa sob plurality, e na seguinte, uma eleição com duas cadeiras em disputa sob o sistema de votos múltiplos não transferíveis. Utilizando uma abordagem por differences-in-differences, as evidências encontradas pelos autores identificam coordenação entre os eleitores, mas não entre as elites, resultando em entradas acima do esperado.

Com uma estratégia de identificação similar à de Crisp e Demirkaya, Lucardi (2017) destaca que o efeito encontrado por estes autores corresponde a um efeito conjunto entre o número de cadeiras em disputa e a fórmula eleitoral, já que a mudança em cada eleição para o Senado brasileiro ocorre tanto em M, quanto na quantidade de votos disponíveis para o eleitor. Para verificar apenas o efeito da magnitude do distrito, Lucardi analisa as mudanças no número de cadeiras em disputa nas eleições argentinas pós-redemocratização.

Argentinos elegem seus deputados federais para cargos de quatro anos, porém a renovação dos mandatos ocorre a cada dois anos, com algo parecido com eleições de meio termo, mas que não colocam todas as cadeiras em disputa. Metade dos assentos estão em competição nas eleições gerais e simultâneas com as de presidente, e a outra metade em eleições dois anos depois. Sendo assim, províncias (distritos) que possuem representação de um número ímpar de parlamentares, possuem diferença no $\mathrm{M}$ entre as duas eleições. Um fator curioso, e que contribui para a identificação causal do trabalho, é o de que a decisão de qual eleição (as simultâneas ou as de meio termo) ficaria com M maior nestas províncias se deu por meio de sorteio em 1983.

Com este desenho de pesquisa, o autor aplica uma abordagem de differences-in-differences, na qual o tratamento é "ligado e desligado a cada dois anos" (p.7) e encontra efeito significativo apenas para variáveis relacionadas à distribuição de assentos (número de listas com cadeiras e Gallagher Index 4 ), enquanto as variáveis relacionadas à coordenação (número de listas na disputa, número efetivo de partidos, votos aos dois primeiros), embora estejam na direção teorizada, não alcançam significância estatística.

\footnotetext{
${ }_{4}$ Gallagher, 1991. A desproporcionalidade é resultado da fórmula: , onde vi representa a proporção de votos do partido i, e si, a proporção de assentos ganhos por este partido.
} 
Dois outros estudos se baseiam em interferências exógenas, mas utilizam métodos distintos. Fiva e Folke (2016) propõem uma abordagem que busca separar os efeitos mecânicos dos psicológicos. Para tanto, aproveitam uma reforma eleitoral realizada para as eleições municipais na Noruega em 2003, na qual os noruegueses deixaram de utilizar o método D’Hondt de alocação das sobras, e adotaram o método Saint-Lague Modificado. Com os dados de eleições anteriores e posteriores a esta mudança, os autores propõe uma abordagem de série de comparações pareadas de resultados eleitorais reais e contrafactuais. Para gerar estes contrafactuais, os autores calculam os indicadores utilizando a mesma distribuição de votos da eleição real, com as regras da eleição anterior ou posterior à mudança. Ou seja, verificam a mudança no número de partidos e índice de desproporcionalidade para as eleições de 1999 (anterior à mudança) com o método D’Hondt e com o Saint-Lague modificado, fazendo o mesmo para as eleições de 2003 (posterior à mudança). Os autores encontram efeito significativo e na direção esperada pela teoria em todas as variáveis.

Por fim, há o estudo de Singer e Gershman (2018), que abordam as mudanças de magnitude que ocorreram devido a mudanças populacionais ou por revisão da regra que estabelece a relação entre população e número de cadeiras. Para tanto, focam em mudanças ao nível do distrito, com o objetivo de superar o obstáculo da endogeneidade que ocorre com maior facilidade ao nível nacional. A ideia é a de que mudanças ao nível do distrito que partem de diretrizes nacionais têm menor probabilidade de serem fruto de manipulações políticas de atores interessados.

Os autores utilizam dados de 20 países para testar os efeitos das mudanças de magnitude sobre a fragmentação eleitoral. Destacam que métodos cross-sectional aplicados pela literatura não são capazes de separar as causas dos efeitos. Portanto, aplicam uma abordagem de first differenced pooled time-series e produzem evidências significativas sobre o efeito da magnitude do distrito sobre o número de partidos. Uma observação interessante que este desenho de pesquisa possibilita sobre estas evidências é a de que o efeito da mudança de M sobre a fragmentação eleitoral, ainda que sempre positivo, diminui na medida em que $\mathrm{M}$ aumenta, ou seja, uma mudança de 9 para 11 cadeiras, provavelmente terá maior efeito sobre o número de partidos do que uma mudança de 30 para 32, por exemplo.

Ainda que a maioria dos trabalhos apontem para a mesma direção, o grau de generalização possível a partir dos resultados apresentados não nos permite avaliar o efeito da magnitude do distrito em sistemas de representação proporcional de lista aberta vigente no Brasil. Como dito anteriormente, temos a peculiaridade de uma magnitude alta em nossos distritos, o que sem dúvida dificulta a coordenação dos atores nos termos propostos por Duverger e Cox, mas que de maneira 
alguma a impossibilita, ou mesmo fecha oportunidades para outros tipos de coordenação. Na próxima seção, alguns testes são realizados para buscar evidências deste comportamento de eleitores e elites partidárias no Brasil.

\section{ANÁLISE EMPÍRICA}

Após a revisão da literatura sobre a relação entre magnitude do distrito e o número de partidos, agora proponho três abordagens para verificar este efeito no sistema de representação proporcional de lista aberta brasileiro, utilizando dados dos municípios.

A primeira abordagem, que ainda está em desenvolvimento, é a aplicação de uma regressão de descontinuidade para verificação do efeito da mudança de magnitude do distrito sobre o número efetivo de partidos a partir de uma série de resoluções do TSE em 2004 que reduziu em 14\% as vagas para vereador no país. Esta mudança possibilita a aplicação de um modelo convencional de regressão de descontinuidade (sharp RDD) pois estabelece um limiar que impõe o número de cadeiras aos municípios. Aqueles que contavam com até 47.619 habitantes, tinham direito a 9 assentos, enquanto os com população entre 47.620 e 95.238 habitantes, passariam a ter 10 cadeiras.

A segunda abordagem é uma de differences-in-differences na qual se considera a mudança de magnitude viabilizada pela aprovação da Emenda Constitucional n. 58 de 2009, que após uma série de conflitos entre municípios, parlamentares e Justiça, redefiniu os limiares populacionais necessários para estabelecer o número de cadeiras em disputa para as câmaras municipais. Esta Emenda redimensionou a proporção de habitantes e cadeiras: 9 cadeiras para municípios com até 15 mil habitantes, 11 para municípios com população entre 15 e 30 mil, 13 para cidades com 30 a 50 mil, e assim por diante. Esta alteração é uma resposta de parlamentares às mudanças proporcionadas pelas resoluções da Justiça Eleitoral, já que possibilita aumento considerável do número de vereadores no país.

A terceira abordagem, também ainda em desenvolvimento, é uma versão da segunda abordagem com regressão de descontinuidade. Neste caso, será utilizado um modelo distinto deste método (fuzzy RDD), que possibilita verificar o efeito causal local da mudança de magnitude para as unidades tratadas, ou seja, apenas para aquelas que poderiam receber o tratamento (possuir entre 15 e 30 mil habitantes) e que de fato o receberam (aprovaram a Lei Orgânica e alteraram a magnitude). 


\subsection{ABORDAGEM POR DIFFERENCES-IN-DIFFERENCES}

Antes de seguir, é importante lidar com um potencial problema para o desenho de pesquisa proposto neste item. Para alterarem a magnitude, os municípios tiveram que se auto selecionar, visto que a alteração dependia de aprovação de uma Lei Orgânica na própria câmara municipal. O problema, então, poderia ser o de que partidos e candidatos se mobilizassem para aprovar esta Lei apenas se encontrassem benefício próprio em tal ato, assim não ultrapassando os obstáculos de endogeneidade da relação entre regras eleitorais e resultados políticos.

Contudo, a expectativa teórica do resultado desta mudança é o aumento da fragmentação eleitoral e partidária, algo que não está na direção esperada sob o entendimento de que partidos e vereadores se mobilizariam para, por exemplo, aumentar a representação de seu grupo, pois, afinal, não faria sentido abrir o mercado eleitoral para melhor desempenho da concorrência. Outro fator neste sentido é o de que o método de distribuição das cadeiras é por si só um obstáculo para manipulações como esta, tendo em vista a grande dificuldade imposta para a antecipação do destino das cadeiras adicionadas.

Partindo das alterações que seguiram a Emenda Constitucional n. 58, selecionei para a amostra do estudo os municípios que possuíam nove cadeiras em 2008 e que ou não mudaram sua magnitude, ou a mudaram para 11 em 2012. Dos 5555 municípios brasileiros em 2008, 4950 tinham $\mathrm{M}=9$, representando 89,10\% dos municípios do país. Destes 5555, 1693 alteraram magnitude entre as eleições de 2008 e 2012, dos quais 884 tinham $\mathrm{M}=9$ em 2008 e passaram para $\mathrm{M}=11 \mathrm{em} 2012$.

Utilizando os termos da literatura de inferência causal, o tratamento, portanto, é o fato de o município ter aumentado sua magnitude do distrito em duas cadeiras. No grupo de controle estão os municípios que não fizeram tal alteração.

De início, são testados os efeitos da mudança sobre duas variáveis amplamente testadas na literatura discutida neste trabalho: o número de partidos (NP) e o número efetivo de partidos (NEP). Enquanto aquele pretende verificar indícios sobre coordenação eleitoral, ou seja, de entrada estratégica por parte das elites partidárias; este traz evidências sobre a coordenação dos eleitores, considerando o voto estratégico.

O principal pressuposto de uma análise por differences-in-differences é a de tendência paralela das variáveis de interesse entre os grupos de tratamento e controle antes da intervenção ocorrer. Os gráficos 1A e 1B indicam que este pressuposto é cumprido para as variáveis 
selecionadas, já que sua evolução temporal segue padrões semelhantes entre os grupos entre as eleições de 2000, 2004 e 2008.

\section{GRÁFICO 1: EVOLUÇÃO TEMPORAL DA MÉDIA DE NÚMERO DE PARTIDOS (A) E DE NÚMERO EFETIVO DE PARTIDOS (B) DE 2000 A 2016.}

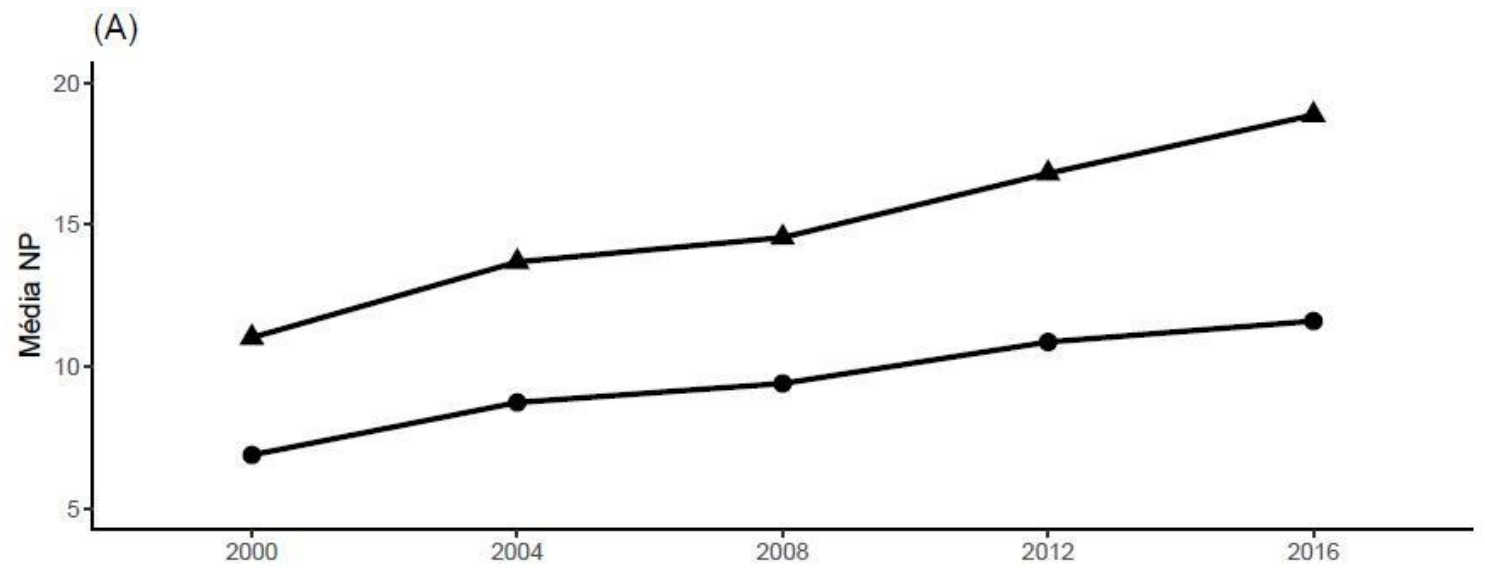

(B)

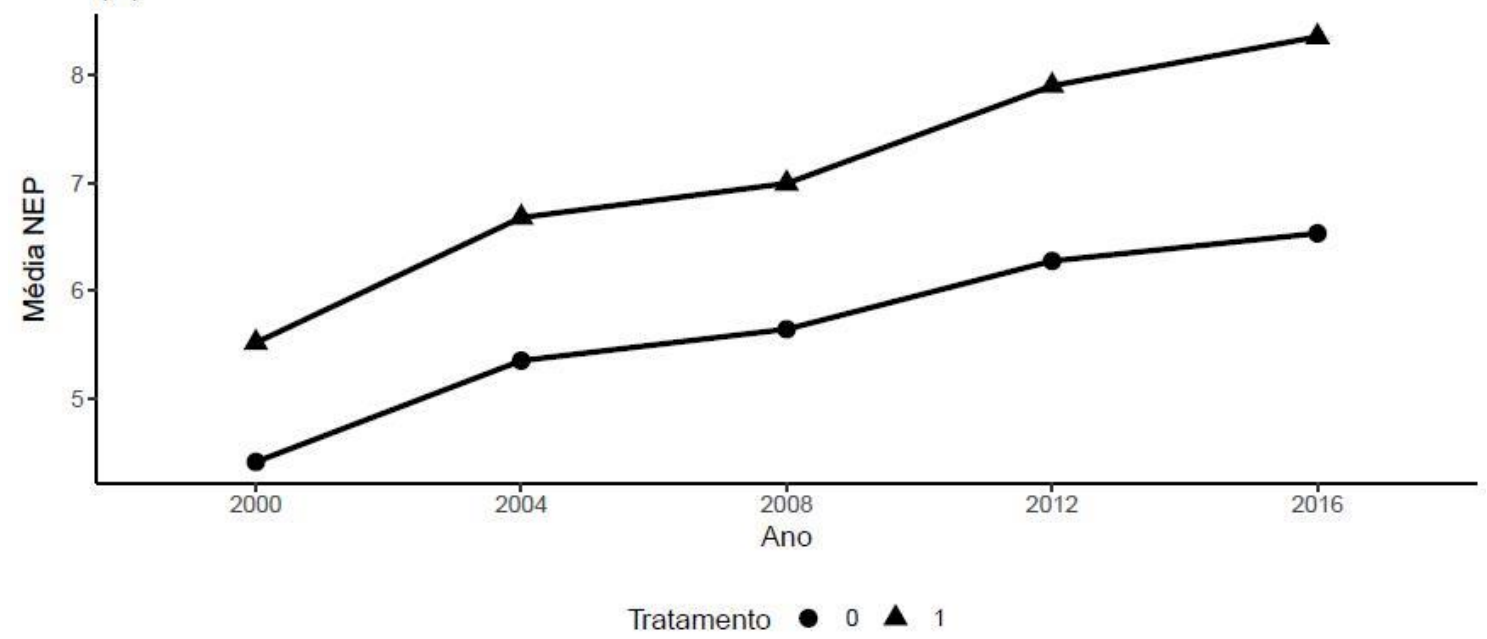

Fonte: elaboração própria a partir dos dados do TSE

Na Tabela 1 são apresentados os resultados da análise. No modelo 1, que tem como variável dependente o número efetivo de partidos (NEP) se nota que o aumento da magnitude do distrito em duas cadeiras desencadeou, em média, um aumento estatisticamente significativo de 0,27 partido efetivo, valor que representa 3,3\% da média de NEP para municípios de magnitude nove em 2008 $(6,03)$ e 2,9\% da média destes em $2012(6,73)$. No modelo 2, verifica-se a robustez deste resultado à inclusão de efeitos fixos por unidade da federação. Com esta inclusão, a significância estatística do efeito do tratamento que estava apenas ao nível de 5\% no modelo 1, passa agora para o nível de $1 \%$. 
Quando se altera a variável dependente para o número bruto de partidos na disputa, o efeito segue na mesma direção. O efeito médio do tratamento sobre o número total de partidos nos municípios selecionados é de 0,67 partido (modelo 3), estatisticamente significante ao nível de 0,01\%. Em termos substantivos, o valor representa 6,6\% da média de partidos em $2008(10,02)$ e $5,7 \%$ em $2012(11,65)$. No modelo 4, novamente os resultados se mostram robustos à inclusão de efeitos fixos por unidade da federação.

TABELA 1: EFEITO DA MUDANÇA DE MAGNITUDE ENTRE AS ELEIÇÕES DE 2008 E 2012 SOBRE O NÚMERO EFETIVO DE PARTIDOS (NEP) E O NÚMERO DE PARTIDOS (NP)

\begin{tabular}{lcccccccc}
\hline & \multicolumn{2}{c}{ (1) NEP } & \multicolumn{2}{c}{ (2) NEP efeitos fixos UF } & \multicolumn{2}{c}{ (3) NP } & \multicolumn{2}{c}{ (4) NP efeitos fixos UF } \\
Predictors & Estimates & $S E$ & Estimates & SE & Estimates & SE & Estimates & $S E$ \\
\hline Intercept & $5.642^{* * *}$ & 0.038 & $6.350^{* * *}$ & 0.333 & $9.051^{* * *}$ & 0.062 & $11.388^{* * *}$ & 0.541 \\
Ano & $0.634^{* * *}$ & 0.053 & $0.634^{* * *}$ & 0.046 & $1.440^{* * *}$ & 0.088 & $1.440^{* * *}$ & 0.075 \\
Tratamento & $1.355^{* * *}$ & 0.086 & $0.997^{* * *}$ & 0.077 & $3.331^{* * *}$ & 0.142 & $2.512^{* * *}$ & 0.126 \\
Ano ${ }^{*}$ Tratamento & $0.272^{*}$ & 0.122 & $0.272^{* *}$ & 0.105 & $0.678^{* * *}$ & 0.201 & $0.678^{* * *}$ & 0.171 \\
\hline $\begin{array}{l}\text { Observations } \\
\mathrm{R}^{2} / \mathrm{R}^{2} \text { adjusted }\end{array}$ & 9226 & & 9226 & & 9226 & 9226 & \\
\hline \hline
\end{tabular}

Como forma de verificar se os resultados encontrados se devem a fatores sistemáticos presentes em todos os pares de eleições, na Tabela 2 apresenta-se um teste placebo utilizando os mesmos grupos mobilizados para os testes da Tabela 1, mas agora com dados anteriores ao tratamento das eleições de 2004 e 2008. Nos modelos de 5 a 8, se pode notar que os coeficientes além de menores que os encontrados acima, não alcançam significância estatística em nenhuma das especificações testadas, fornecendo evidência favorável, portanto, ao fato de que o efeito encontrado nos modelos de 1 a 4 se deve mesmo ao tratamento.

TABELA 2: TESTE PLACEBO COM DADOS PRÉ TRATAMENTO (2004 E 2008) 


\begin{tabular}{lcccccccc}
\hline \hline & \multicolumn{2}{c}{ (5) NEP } & \multicolumn{2}{c}{ (6) NEP efeitos fixos UF } & \multicolumn{2}{c}{ (7) NP } & \multicolumn{2}{c}{ (8) NP efeitos fixos UF } \\
Predictors & Estimates & $S E$ & Estimates & $S E$ & Estimates & SE & Estimates & $S E$ \\
\hline Intercept & $5.350^{* * *}$ & 0.035 & $5.584^{* * *}$ & 0.307 & $8.381^{* * *}$ & 0.056 & $9.655^{* * *}$ & 0.496 \\
Ano & $0.292^{* * *}$ & 0.049 & $0.292^{* * *}$ & 0.043 & $0.670^{* * *}$ & 0.080 & $0.670^{* * *}$ & 0.069 \\
Tratamento & $1.329^{* * *}$ & 0.079 & $1.059^{* * *}$ & 0.071 & $3.099^{* * *}$ & 0.128 & $2.445^{* * *}$ & 0.115 \\
Ano ${ }^{*}$ Tratamento & 0.025 & 0.112 & 0.025 & 0.097 & 0.232 & 0.182 & 0.232 & 0.157 \\
\hline Observations & 9225 & & 9225 & & 9225 & 9225 & \\
$\mathrm{R}^{2} / \mathrm{R}^{2}$ adjusted & $0.063 / 0.063$ & $0.295 / 0.293$ & & $0.128 / 0.128$ & $0.351 / 0.349$ & \\
\hline \hline
\end{tabular}

Os resultados das Tabelas 1 e 2 mostram que o aumento de magnitude do distrito estudado causou aumento tanto no número de partidos entrando na disputa, quanto no número efetivo de partidos recebendo votos. O aumento de NP aponta para o desafio posto pelo aumento de $\mathrm{M}$ sobre a coordenação de entrada por parte das lideranças partidárias. Ao mesmo tempo em que abre oportunidade para outros partidos, o tratamento embaralha as expectativas dos atores, algo que pode ser também percebido pelo aumento de NEP, com eleitores dispersando o voto. Como se percebe, efeitos mecânicos e psicológicos se sobrepõe na explicação do resultado encontrado, em futuras versões deste trabalho pretendo aplicar a técnica utilizada por Fiva e Folke (2016) como tentativa de desembaraçar estes efeitos.

Por fim, testarei o efeito do tratamento sobre o número efetivo de partidos com assentos. A escolha de adicionar esta especificação de variável dependente ocorre pela sua capacidade de traduzir a fragmentação partidária nas câmaras municipais. O gráfico 2 verifica se há tendência paralela na série temporal desta variável entre os grupos. Nota-se que houve aumento maior no NEP com assentos no grupo controle entre as eleições de 2000 e 2004, algo que não chega a inviabilizar a análise proposta, já que o problema estaria presente se houvesse comportamento sistemático que fizesse com que a variável dependente crescesse sempre em uma taxa maior para o grupo de tratamento. Além disso, pode-se notar tendência semelhante entre as eleições de 2004 e 2008.

\section{GRÁFICO 2: EVOLUÇÃO TEMPORAL DA MÉDIA DE NÚMERO EFETIVO DE PARTIDOS}

COM ASSENTOS DE 2000 A 2016 


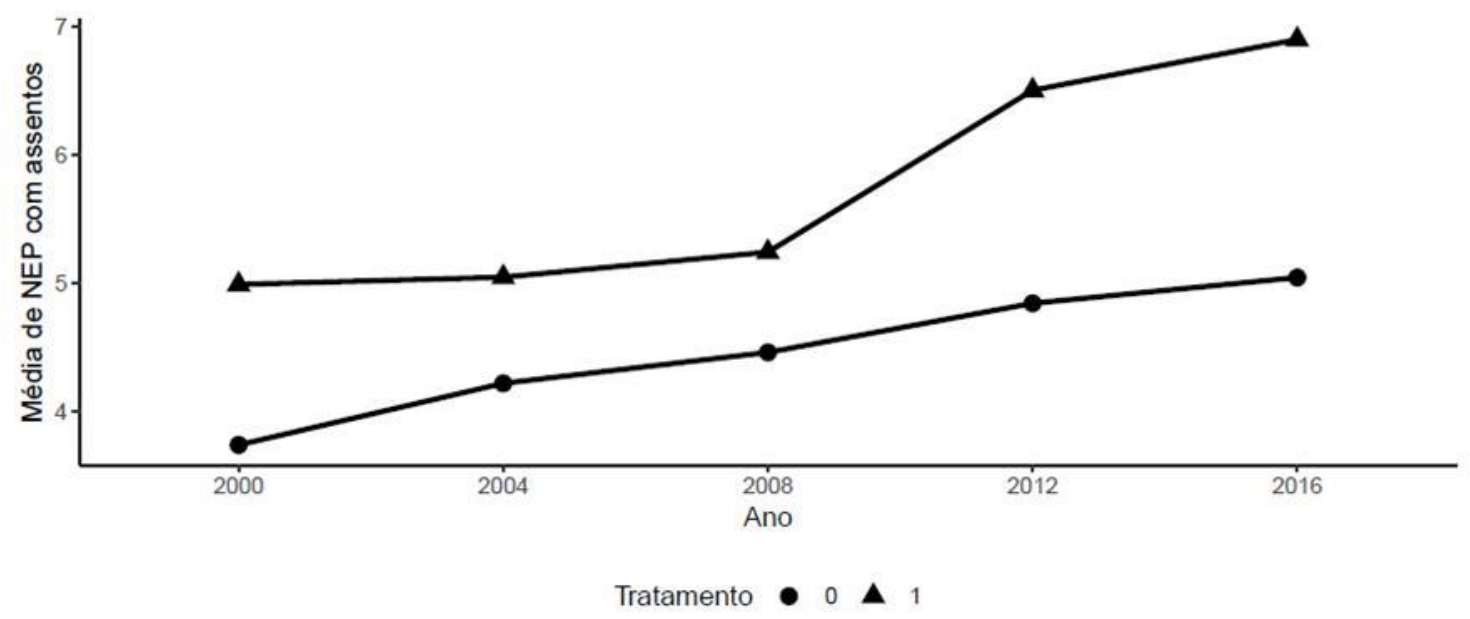

Fonte: elaboração própria a partir dos dados do TSE

Tendo isto em vista, na Tabela 3 estão os modelos utilizados para verificar o efeito do tratamento sobre o NEP com assentos. No modelo 10, nota-se que, em média, o tratamento causou aumento de 0,54 partido efetivo com assento nas câmaras dos municípios na amostra, um resultado estatisticamente significante ao nível de $0,01 \%$, que é robusto à inclusão de efeitos fixos por unidade da federação. Como realizado nos testes anteriores, aqui também há um teste placebo com os dados de 2004 e 2008, que encontra um coeficiente muito menor e que não alcança significância estatística.

TABELA 3: EFEITO DA MUDANÇA DE MAGNITUDE ENTRE AS ELEIÇÕES DE 2008 E 2012 SOBRE O NÚMERO EFETIVO DE PARTIDOS (NEP) COM ASSENTOS E TESTE PLACEBO COM DADOS DE 2004 E 2008

\begin{tabular}{lcccccc}
\hline & \multicolumn{2}{c}{$(\mathbf{1 0})$ NEP com assentos } & \multicolumn{2}{c}{ (11) Efeitos fixos por UF } & \multicolumn{2}{c}{ (12) Placebo } \\
Predictors & Estimates & $S E$ & Estimates & $S E$ & Estimates & $S E$ \\
\hline Intercept & $4.399^{* * *}$ & 0.024 & $4.499^{* * *}$ & 0.227 & $4.168^{* * *}$ & 0.022 \\
Ano & $0.570^{* * *}$ & 0.055 & $0.377^{* * *}$ & 0.053 & $0.529^{* * *}$ & 0.051 \\
Tratamento & $0.373^{* * *}$ & 0.034 & $0.373^{* * *}$ & 0.031 & $0.232^{* * *}$ & 0.031 \\
Ano Tratamento & $0.538^{* * *}$ & 0.078 & $0.538^{* * *}$ & 0.072 & 0.042 & 0.072 \\
\hline Observations & 9226 & & 9226 & & 9225 & \\
$\mathrm{R}^{2} / \mathrm{R}^{2}$ adjusted & $0.075 / 0.075$ & & $0.219 / 0.217$ & & $0.032 / 0.032$ \\
\hline \hline
\end{tabular}


Portanto, com as análises mobilizadas até o momento, verifica-se que o aumento de magnitude do distrito em sistemas proporcionais de M elevada causa maior fragmentação partidária ao nível do distrito.

\section{CONSIDERAÇÕES FINAIS}

Após revisão de parte da literatura relevante para a pergunta de pesquisa proposta, a apresentação dos testes iniciais indica efeito causal significativo da mudança da magnitude dos distritos sobre a fragmentação partidárias nos municípios pequenos do país. Dessa forma, encaminha-se o entendimento de que mesmo em distritos de alta magnitude, o comportamento estratégico dos atores responde às regras eleitorais, já que o aumento do número de assentos em disputa tende a causar descoordenação tanto das elites partidárias (fenômeno traduzido pelo número total de partidos que entram no pleito), quanto dos eleitores (traduzido pelo número efetivo de partidos).

Análises sobre causas e consequências da fragmentação do sistema partidário brasileiro também não são novidade e serão consideradas em futuras versões do trabalho com a finalidade de decifrar os resultados aqui encontrados em termos mais substantivos. Nesta direção, um enfoque qualitativo para estas questões pode ajudar a interpretação.

Uma vez mais, frisa-se que ainda há alternativas de técnicas e desenhos de pesquisa a serem aplicados e que, portanto, os resultados encontrados são parciais.

\section{REFERÊNCIAS}

Amorim Neto, Octavio, e Cox, Gary. (1997). Electoral institutions, cleavage structures and the number of parties. American Journal of Political Science, 41, 149-174.

Boas, Taylor e Hidalgo, Daniel (2011). Controlling the airwaves: incumbency advantage and community radio in Brazil. American Journal of Political Science, vol. 55, 869-885.

Campbell, Peter (1958) French Electoral Systems and Elections 1789-1957. London: Faber and Faber.

Chan, Eric e Golden, Mirian (2007). Electoral systems, district magnitude and corruption. B. J. Pol. S. 37. 
Clark, William e Golder, Matt (2006). Rehabilitating Duverger's theory: testing the mechanical and strategic modifying effects of electoral laws. Comp. Polit. Stud. 39, 679-708.

Cox, Gary (1997). Making Votes Count: Strategic Coordination in the World's Electoral Systems. Cambridge University Press.

Coppedge, Michael (1997). District magnitude, economic performance, and party-system fragmentation in five Latin American countries. Comparative Political Studies, 30.

Crisp, Brian e Demirkaya, Betul (2019) Strategic entry and strategic voting in majoritarian systems. The Journal of Politics, 82.

Duverger, Maurice. (1970 [1951]). Os partidos políticos. São Paulo: Zahar.

Edwards, Martin e Thames, Frank (2007). District magnitude, personal votes, and government expenditures. Elecotal Studies, 26.

Ferree, Karen; Bingham Powell; G., Scheiner, Ethan (2014). Context, electoral rules, and party systems. Annu. Rev. Polit. Sci. 17, 421-439.

Filho, Gilberto (2010). Da constituinte à Emenda Constitucional nº58 de 2009: o Poder Judiciário, o Congresso Nacional e a composição das Câmaras de Vereadores. Revista de Informação Legislativa, n.187, 109-124.

Fiva, Jon H., e Olle Folke (2016). Mechanical and Psychological Effects of Electoral Reform. British Journal of Political Science 46 (2):265-79.

Fujiwara, Thomas. (2011). A Regression Discontinuity Test of Strategic Voting and Duverger's Law. Quarterly Journal of Political Science 6 (3-4):197-233.

Gallagher, M. (1991) Proportionality, disproportionality and electoral systems. Electoral Studies 10, 33-51.

Grumm, J. G. (1958). Theories of Electoral Systems. Midwest Journal of Political Science 2:357376.

Guarnieri, Fernando (2015). Voto estratégico e coordenação eleitoral: testando a Lei de Duverger no Brasil. Revista Brasileira de Ciências Sociais, vol. 30, n.89.

Laakso, Markku e Taagepera, Rein (1979). "Effective" number of parties: a measure with application to West Europe. Comparative Political Studies, 12. 
Lijphart, Arend (1990). The Political Consequences of Electoral Laws, 1945-85. The American Political Science Review, 84, pp 481-496.

Lucardi, Adrián (2017). The effect of district magnitude on electoral outcomes: evidence from two natural experiments in Argentina. Br. J. Polit. Sci. 49, 557-577.

Moser RG, Scheiner E. (2012). Electoral Systems and Political Context: How the Effects of Rules Vary Across New and Established Democracies. New York: Cambridge Univ. Press

Ordeshook, Peter, \& Shvetsova, Olga. (1994). Ethnic heterogeneity, district magnitude, and the number of parties. American Journal of Political Science, 38, 100-123.

Rae, Douglas (1967). The Political Consequences of Electoral Laws. New Haven, CT: Yale Univ. Press

Riker, W. H. (1986), “Duverger's Law revisited”, in B. Gofman e A. Lijphart, Electoral laws and their political consequences, Nova York, Aghaton Press.

Riker, William. (1982). The two-party system and Duverger's law: An essay on the history of political science. American Political Science Review, 76, 753-766.

Shugart, Matthew (2005). Comparative electoral systems research: the maturation of a field and new challenges ahead. In The Politics of Electoral Systems, ed. M Gallagher, P Mitchell, pp. 2556. Oxford, UK: Oxford Univ. Press

Singer, Matthew; Gershman, Zachary (2018). Do changes in district magnitude affect electoral fragmentation? Evidence over time at the district level. Electoral Studies, vol.54.

Taagepera, Rein, Shugart, Matthew (1989). Seats and Votes: the Effects and Determinants of Electoral Systems. Yale University Press, New Haven, CT. 